\title{
Perspective
}

\section{Sustainable water environment and water use: A perspective on water resource utilization}

\author{
Huijuan Liu ${ }^{1, *}$, Dongsheng Wang ${ }^{1}$, Baoling Yuan ${ }^{2}$ \\ 1. State Key Laboratory of Environmental Aquatic Chemistry, Research Center of Eco-Environment Sciences, Chinese Academy of Sciences, \\ Beijing 100085, China \\ 2. Institute of Municipal and Environmental Engineering, College of Civil Engineering, Huaqiao University, Xiamen 361021, China
}

\begin{abstract}
The 6th International Water Association Asia Pacific Regional Grouping (IWA-ASPIRE) Conference and Exhibition was held on September 20-24, 2015, in Beijing. The conference was hosted by the Research Center for Eco-Environmental Sciences (RCEES) of Chinese Academy of Sciences (CAS); with strong support provided by CAS, Chinese Academy of Engineering (CAE), National Science Foundation of China (NSFC), the Key Laboratory of Drinking Water Science and Technology of CAS, the joint CAS-The World Academy of Sciences Centre of Excellence for Water and Environment (CASTWAS-CEWE), Expert Committee China's Conceptual Wastewater Treatment Plant and Beijing Capital Co., Ltd. along with many others. The International Water Association (IWA) president Helmut Kroiss, executive president Ger Bergkamp and past IWA president Glenn Daigger and David Gament also attended the conference. The more than 700 delegates in attendance came from China, Japan, Korea, Malaysia, Thailand, Vietnam, Switzerland, Singapore, Chinese Taiwan, Chinese Hong Kong, United States of America, Norway and France with universities, research institutes, industry and water management departments representing more than 10 countries and regions.

The theme of this conference was "Sustainable Water Environment and Water Use" and was split into 18 special topics including, alternative water resources, diffuse pollution control and management, drinking water treatment and distribution, sustainable water environment, water quality monitoring and modeling and others. Nine workshops were setup including a "Summit for Conceptual Wastewater Treatment Plants", "IWA Young Scholar Water Forum",
\end{abstract}

"CAS-TWAS-CEWE Forum", and "Water Conservation and Water Safety Forum" including others. The conference discussed some current hot topics and themes for a very successful academic and application exchange on the water environment and water use. Based on the symposia, forums and discussions, several very important research and development trends were put forward. These included: water environment risk control and management, "clean" water treatment processes, green watershed construction, and the sustainable water resource model innovation. These topics not only reflect the current needs of the water environment and water resources of the Asia-Pacific region but also issues of great importance to the international community.

Globally, it is undisputed that many regions are facing the severe challenges of water pollution and water shortages; especially in the Asian region where these problems have become prominent forefront issues. We are now fully aware that the key problems of the water environment originate from changes in water quality, which can in turn lead to potential ecological and health risks, which have made chemical micro-pollutants a major global concern. With increasing complexity of sources of water pollution as well as continuous progress in research and detection methods, even more chemical pollutants have been found in the aquatic environment. These pollutants may produce some individual or combined effects that lead to mutagenic and toxic outcomes; many of which are continuously being revealed. Research has shown that many important global watersheds have been found to contain trace level persistent organic pollutants, endocrine disrupting chemicals, pharmaceuticals

\footnotetext{
* Corresponding author. E-mail: hjliu@rcees.ac.cn (Huijuan Liu).
} 
and personal care products and other new pollutants that have resulted in potential ecological risks in some water bodies. Therefore, research on the ecological effects of micro-pollutants and simultaneous impact on the water environment has continued to garner increased attention, especially regarding control of chemical pollution sources at the watershed level scale.

To meet more stringent requirements for water micropollutants and ecological risk control, "clean" water treatment processes have become an irreplaceable key focal point of research to address these concerns. Water treatment theory and research on technologies and application should not only emphasize the safety of water quality, but also should increase emphasis on low energy consumption processes, low chemical use and low waste emissions. Therefore, sewage treatment is no longer only the removal of pollutants but to actively explore ways for water reuse, organic matter energy conversion and nutrient recovery, and trying to achieve source pollutant reduction by using these processes. At the same time, drinking water research has paid more attention to the health risk control, and the combined pollution have become a hot topic People recognize that drinking water purification systems based on limited indicators have been unable to adapt to complicated water quality issues and pollution control. So we put forward a new vision for drinking water safety insurance: synergistic control based on water quality standards and health effects. Summarizing these new ideas and achievement, this conference puts forward the new mission of the next generation water treatment plant: treatment technology is green; treatment processes is of the lowest consumption in chemical and energy; and treated water quality is safe for the ecosystem and human health.

To ensure water environment and water ecology security, we must design the green watershed with low emissions, high self-purification ability, ecosystem healthy, and excellent service functions. We should learn from the experience of developed countries on their successful watershed governance and management. On the basis of water environment capacity and carrying capacity, the basic characteristics within the watershed should be investigated in-depth to determine key factors and processes that influence the ecosystem and service functions. An integrated technology management system should be built for watershed pollution control, watershed risk management and smart management methods fitting for the Asia-Pacific region.

Creating an excellent and sustainable water environment, is a synergistic process in which an effective solution cannot be reached by just considering single aspects. Past IWA president, Professor Glenn Diagger introduced the concept of "one water" several years ago, meaning that all the water on earth is in essence available for usage. Therefore, multipurpose reuse of re-claimed water, ecological storage of rainwater and reclaimed water, sea water desalinization, water savings, pollution control and water ecological restoration have become an important way to construct a sustainable water resource system, and in current and future decades are set to become an internationally significant research area. Accordingly, there is a common belief that sewage is not "just" waste, but an important water resource with considerable amounts of energy and materials. For this reason, this conference conducted a special seminar on "the future oriented design of conceptual sewage treatment plants in China." In which many world-class experts conducted an open discussion, consensus on reclaimed water quality safety, energy self-sufficiency, resource recycling and eco-friendly design is looking forward to Chinese to lead international research and development in this new direction.

With support from the IWA and various other parties, the conference was a huge success to enhance academic and water professional cooperation in the Asia-Pacific region. This has also been significant for setting a clear development direction for the water environment and water resource utilization and showcasing the level of scientific work and technology from China to the Asia-Pacific region. We firmly believe that the Asia-Pacific region's water environment and water resources will have a safe and healthy future.

\section{Acknowledgments}

I would like to convey my sincerest thanks to all the organizations and friends who have contributed to make this conference a huge success. 